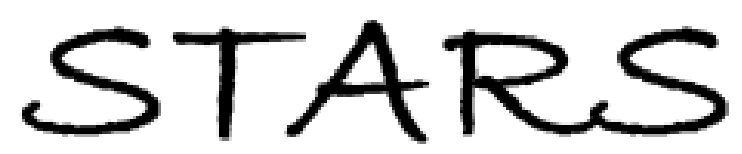

University of Central Florida

STARS

Faculty Bibliography 2010s

Faculty Bibliography

$1-1-2015$

\title{
Mechanical Behavior of Nanostructured Materials
}

Ning $\mathrm{Hu}$

Xi-Qiao Feng

Shao-Yun Fu

Cheng Yan

Guang-Ping Zhang

See next page for additional authors

Find similar works at: https://stars.library.ucf.edu/facultybib2010

University of Central Florida Libraries http://library.ucf.edu

This Editorial Material is brought to you for free and open access by the Faculty Bibliography at STARS. It has been accepted for inclusion in Faculty Bibliography 2010 s by an authorized administrator of STARS. For more information, please contact STARS@ucf.edu.

\section{Recommended Citation}

Hu, Ning; Feng, Xi-Qiao; Fu, Shao-Yun; Yan, Cheng; Zhang, Guang-Ping; and Gou, Jihua, "Mechanical Behavior of Nanostructured Materials" (2015). Faculty Bibliography 2010s. 6579.

https://stars.library.ucf.edu/facultybib2010/6579

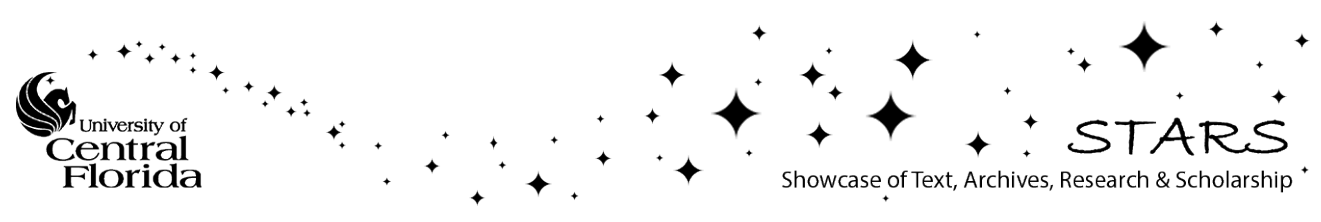


Authors

Ning Hu, Xi-Qiao Feng, Shao-Yun Fu, Cheng Yan, Guang-Ping Zhang, and Jihua Gou 


\title{
Mechanical Behavior of Nanostructured Materials
}

\author{
Ning Hu, ${ }^{1}$ Xi-Qiao Feng, ${ }^{2}$ Shao-Yun Fu, ${ }^{3}$ Cheng Yan, ${ }^{4}$ Guang-Ping Zhang, ${ }^{5}$ and Jihua Gou ${ }^{6}$ \\ ${ }^{1}$ College of Aerospace Engineering, Chongqing University, Chongqing 400044, China \\ ${ }^{2}$ College of Aerospace Engineering, Tsinghua University, Beijing 100084, China \\ ${ }^{3}$ Technical Institute of Physics and Chemistry, Chinese Academy of Sciences, Beijing 100190, China \\ ${ }^{4}$ School of Chemistry, Physics and Mechanical Engineering, Queensland University of Technology, GPO Box 2434, \\ Brisbane, QLD 4000, Australia \\ ${ }^{5}$ Shenyang National Laboratory for Materials Science, Institute of Metal Research, Chinese Academy of Sciences, \\ Shenyang 110016, China \\ ${ }^{6}$ Department of Mechanical and Aerospace Engineering, University of Central Florida, Orlando, FL 32816, USA
}

Correspondence should be addressed to Ning Hu; ninghu@cqu.edu.cn

Received 16 March 2015; Accepted 16 March 2015

Copyright (c) 2015 Ning Hu et al. This is an open access article distributed under the Creative Commons Attribution License, which permits unrestricted use, distribution, and reproduction in any medium, provided the original work is properly cited.

This Special Issue presents recent research advances in various aspects of advanced nanomaterials including synthesis, micro- and nanostructures, mechanical properties, modeling, and applications for material nanotechnology community. In particular, it aims to reflect recent advances in mechanical behaviors, for example, stiffness, strength, ductility, fatigue, and wear resistance, of various nanomaterials including nanocrystalline, inorganic, nonmetallic nanomaterials, composites with nanosized fillers, and biomaterials with nanosized structures. The role of this Special Issue is to bridge the gaps among fabrication techniques, experimental techniques, numerical modeling, and applications for some new nanomaterials and to investigate some key issues related to the mechanical properties of the nanomaterials. It brings together researchers working at the frontier of the mechanical behavior of nanomaterials.

Nanomaterials are truly multidisciplinary. Technically most important properties are mechanical, electrical, catalytic, magnetic, optical, and so forth. Research at the nanoscale material frontier needs to be unified by sharing knowledge, techniques, and expertise on atomic, molecular, and microinteractions. In particular, regarding the mechanical properties, despite the progress made in technology of such materials, their application is still restricted by insufficient experimental data, numerical modeling results, and their interpretation. This applies to the knowledge describing mechanical behaviors of the above nanomaterials under various conditions, for example, static, dynamic, monotonic, and cyclic conditions, at low and high temperatures. The articles of this Special Issue are grouped in the following main topics: (1) numerical modeling and evaluation of mechanical properties of various nanomaterials; (2) preparation and fabrication technologies and their effects on the mechanical properties of various nanomaterials; (3) experimental characterization of mechanical properties of various nanomaterials.

In the first group, by virtue of molecular dynamics simulations or other numerical means, there are some papers dealing with the mechanical properties of some typical nanomaterials, for example, carbon nanotubes. For example, in aspect of molecular dynamics simulations, the mechanical and structural properties of some collapsed carbon nanotubes and the effects of geometric parameters of carbon nanotubes, such as length, diameter, and chirality, were investigated at atomic scale. The dependence of newly formed rippled structure of the carbon nanotubes after relaxation on the chirality was interestingly uncovered. Moreover, the effect of temperature on the tensile property of single-walled carbon nanotubes processed by a surface Ni-coating technology was explored by molecular dynamics simulations. Due to coated $\mathrm{Ni}$, the possibility of degraded mechanical properties of the single-walled carbon nanotubes was demonstrated. Also, the interaction between hydrogen and carbon nanotubes 
was studied using molecular dynamics simulations, and the mechanisms of hydrogen transport in flexible-wall narrow carbon nanotubes were uncovered. Furthermore, at micro/ nanoscale, the interaction potential between parabolic rotator and a particle located outside the rotator was numerically studied on the basis of a negative exponential pair potential between particles. It was found that curvatures and the gradient of curvatures are the essential elements forming the driving forces. Through the idealized numerical experiments, the accuracy of the curvature-based potential was preliminarily proven.

The second group collects the research works regarding preparation and fabrication technologies and their effects on the mechanical properties of various nanomaterials. For instance, the mechanical and tribological properties of dental nanocomposites and the effects of acidic solutions were investigated in detail. Compared with microscale fillers, nanoscale fillers can effectively improve the mechanical properties of the dental nanocomposites, for example, hardness and elastic modulus. Also, the acidic solutions can change the failure mechanisms of the dental nanocomposites under the condition of wearing. Moreover, a new fabrication technology which combines rotary chemical vapor deposition and spark plasma sintering together for $\mathrm{Al}_{2} \mathrm{O}_{3}$ - $\mathrm{Cu}$ nanocomposites was proposed. The positive effects of $\mathrm{Cu}$ nanoparticles on the nanocomposites' fracture toughness were experimentally confirmed. Moreover, a matrix modification technique by using carbon nanotubes and n-butyl glycidyl ether was developed. The interlaminar fracture toughness of glass fiber/epoxy nanocomposites at cryogenic temperature was confirmed to be increased significantly.

Finally, the papers in the third group describe experimental evaluation of properties of various nanomaterials. For instance, the micromechanical behaviors of single-crystal superalloy with different crystal orientations were characterized by microindentation technology. The reduction of the microhardness $\mathrm{H}$ due to dislocation hardening and the relationship between Young's modulus $\mathrm{E}$ and interplanar spacing and crystal variable were confirmed experimentally. Furthermore, a simplified material model was proposed to consider the various crystal orientations, and it was verified by a 3D microindentation simulation approach. As for the mechanical and flame retardant and smoke properties of bamboo-wood hybrid scrimber filled by two kinds of nanoparticles, that is, calcium and magnesium, a detailed exploration about the experimental characterization of the above properties was carried out. The confirmation of the improvement of the above physical and mechanical properties after adding the nanoparticles was also obtained.

We first want to congratulate the authors who made this Special Issue possible. Sincere thanks are due to the reviewers for their very accurate and voluntary job. This is the first time the Journal of Nanomaterials had a Special Issue focusing on mechanical properties of various advanced nanomaterials as well as the influences of fabrication techniques, microstructures, and so forth, on them, from the aspects of the numerical and experimental approaches. It should be very helpful to enhance the effective applications of these advanced nanomaterials. We are grateful to this journal for the support given to the approval and realization of this Special Issue.

$$
\begin{array}{r}
\text { Ning Hu } \\
\text { Xi-Qiao Feng } \\
\text { Shao-Yun Fu } \\
\text { Cheng Yan } \\
\text { Guang-Ping Zhang } \\
\text { Jihua Gou }
\end{array}
$$



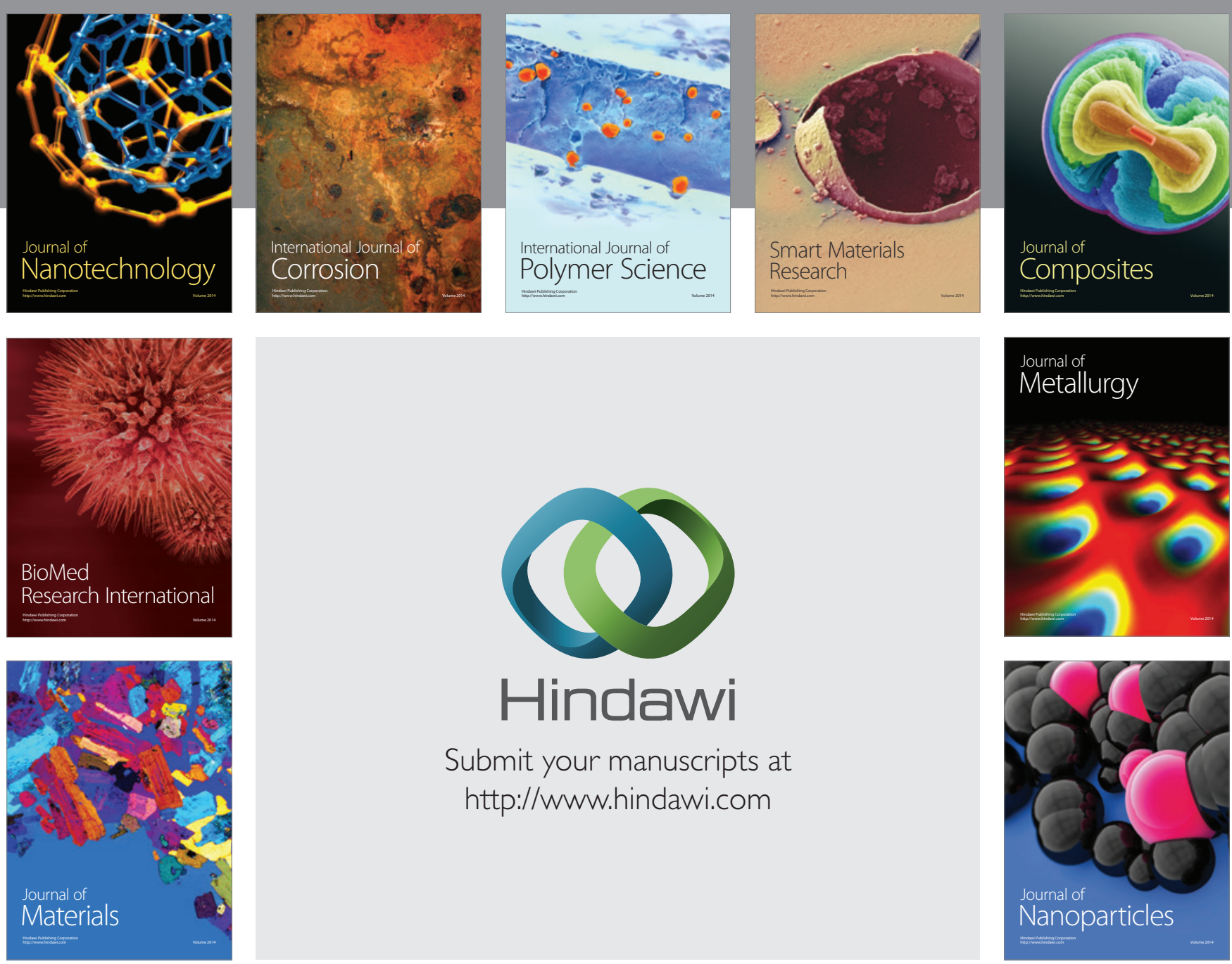

Submit your manuscripts at http://www.hindawi.com
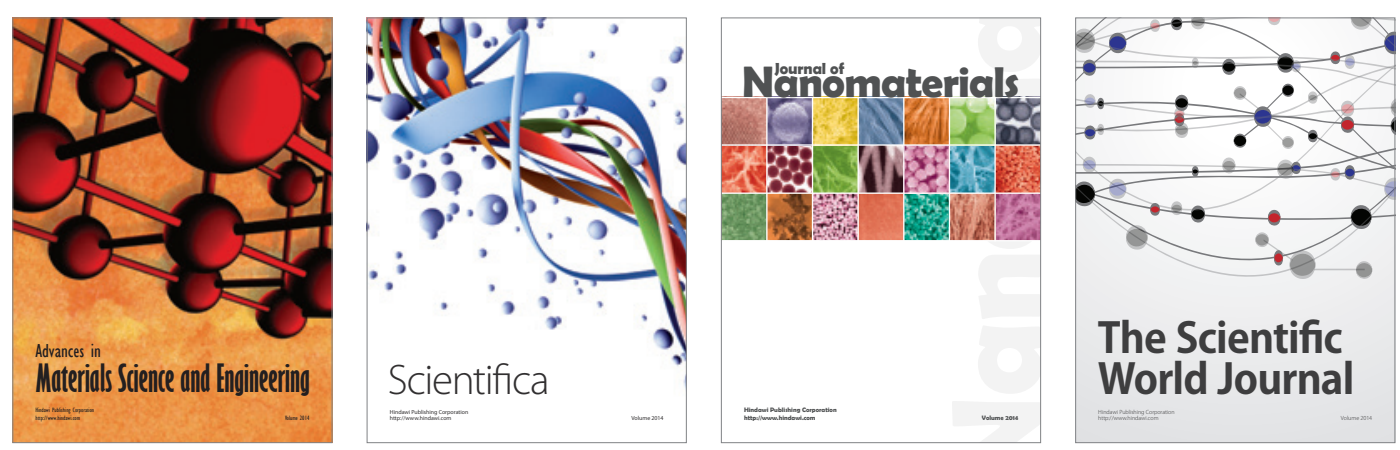

\section{The Scientific World Journal}
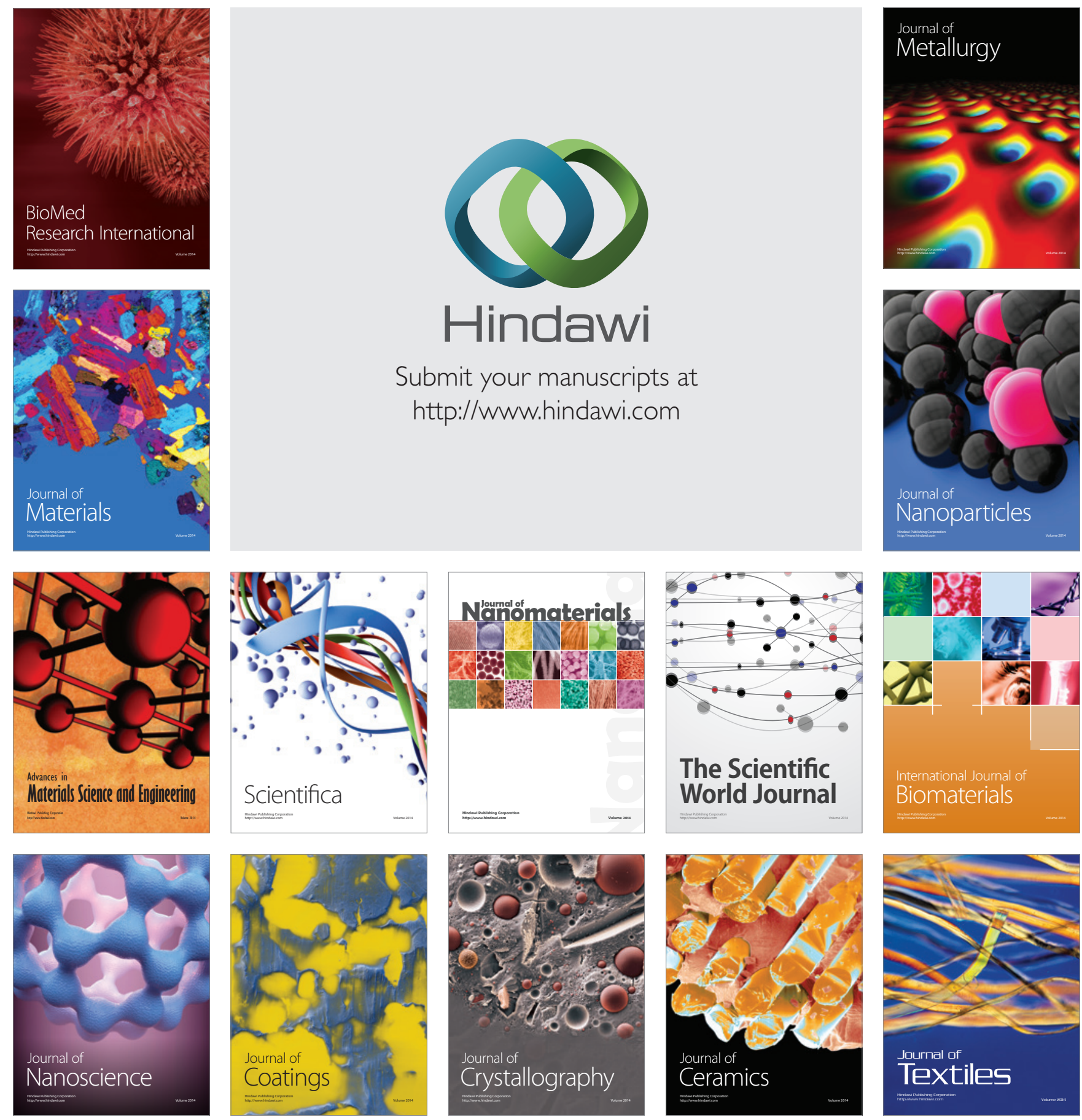